\title{
Effects of 5-fluorouracil, adriamycin and irinotecan on HSC-39, a human scirrhous gastric cancer cell line
}

\author{
RIE TAMAKI $^{1,2}$, AYA KANAI-MORI ${ }^{1}$, YUTA MORISHIGE ${ }^{1}$, ATSUSHI KOIKE ${ }^{1}$, \\ KAZUYOSHI YANAGIHARA ${ }^{1,3}$ and FUMIO AMANO ${ }^{1}$ \\ ${ }^{1}$ Laboratory of Biodefense and Regulation, Osaka University of Pharmaceutical Sciences, Takatsuki, Osaka; \\ ${ }^{2}$ Clinical Trial Management Center, Kobe City Medical Center General Hospital, Kobe, Hyogo; \\ ${ }^{3}$ Research Center for Innovative Oncology, National Cancer Center Hospital East, Kashiwa, Chiba, Japan
}

Received November 4, 2016; Accepted January 18, 2017

DOI: $10.3892 / o r .2017 .5470$

\begin{abstract}
Therapies for patients with scirrhous gastric cancer remain ineffective. Current treatments for gastric cancer based on systemic therapy, such as the combination of S-1 with cisplatin or docetaxel, show good clinical response rates. S-1 plus cisplatin is the standard treatment for HER2-negative advanced scirrhous gastric cancer in Japan. In spite of recent advances in the treatment of gastric cancer, a standard chemotherapy regimen is yet to be established for scirrhous gastric cancer. To develop new therapeutic approaches based on characteristic biological features of cancer cells, we examined the mechanisms underlying the cytotoxicity of anticancer drugs and reactive oxygen species (ROS) toward a human scirrhous cancer cell line, HSC-39, in vitro. Anticancer drugs such as 5-fluorouracil (5-FU), adriamycin (ADR) and irinotecan (CPT-11), as well as ROS, were previously shown to have important cytotoxic effects on these tumor cells. We demonstrated that 5-FU effectively induced apoptosis in HSC-39 cells in a dose-dependent manner, while ADR and CPT-11 induced necrosis and/or aponecrosis. 5-FU effectively inhibited WST-1 decrease in the MTT viability assay, even at low doses where little LDH release was observed, while ADR and CPT-11 only inhibited WST-1 decrease at high doses where LDH release was induced. Moreover, HSC-39 cells showed high sensitivity to $\mathrm{H}_{2} \mathrm{O}_{2}$ and NOC-18, but less sensitivity to other ROS, suggesting a link between cell damage and membrane permeability changes induced by $\mathrm{H}_{2} \mathrm{O}_{2}$ and NOC-18 or related oxygen radical species such as $\mathrm{OH} \cdot$ or $\cdot \mathrm{O}_{2}$. These results suggest that combination treatment of chemotherapeutics with a fluoropyrimidine such as 5-FU is effective chemotherapy for scirrhous gastric cancer.
\end{abstract}

Correspondence to: Dr Fumio Amano, Laboratory of Biodefense and Regulation, Osaka University of Pharmaceutical Sciences, 4-20-1 Nasahara, Takatsuki, Osaka 569-1094, Japan

E-mail: amano@gly.oups.ac.jp

Key words: human gastric scirrhous cancer, HSC-39 cell line, 5-fluorouracil, adriamycin, irinotecan, apoptosis, reactive oxygen species

\section{Introduction}

Scirrhous gastric cancer is unique and tends to spread over the peritoneum with rapid growth and early metastasis (1-4). The prognosis for patients with scirrhous gastric carcinoma remains very poor, with the 5-year survival rate being low. However chemotherapy for other types of gastric cancer has improved, with good results being obtained in Japan (5-9).

HSC-39 cells are a cell line established from pleural effusion of a Japanese male scirrhous gastric cancer patient (10), and can be used to test therapies for scirrhous gastric cancer in vitro. HSC-39 cells are round, freely floating and tend to aggregate loosely in tissue culture medium. In addition, they have characteristics similar to those of the original ascitic tumor cell phenotypes of signet ring cell carcinoma (11). HSC-39 cells have a mutation in exon7 of the p53 gene, which provides a possible selective advantage for tumor cell proliferation (12). Since these cells were derived from a human scirrhous gastric carcinoma patient, they possess the appropriate phenotypes, including histological characteristics and metastatic ability in vitro, on which to test new therapies for scirrhous gastric cancer.

The chemotherapeutic agents 5-fluorouracil (5-FU), adriamycin (ADR) and irinotecan (CPT-11), as well as reactive oxygen species (ROS), have all been reported to be cytotoxic towards tumor cells. Among anticancer drugs for gastric cancer, S-1, a 5-FU analog, has recently become the standard first-line chemotherapeutic drug in Japan, while several other new drugs, including the topoisomerase I inhibitors CPT-11 and ADR, are less frequently used $(13,14)$. These drugs provide an improved prognosis for advanced gastric cancer $(6,15)$. ROS, including non-radical hydrogen peroxide $\left(\mathrm{H}_{2} \mathrm{O}_{2}\right)$, organic hydroperoxide $(\mathrm{ROOH})$, and hypochlorous acid ( $\mathrm{HClO})$, are generated from inflammatory immune cells such as activated macrophages and neutrophils, which accumulate at sites of inflammation. ROS are important for the induction of apoptosis not only in inflammatory cells, but also in neighboring cells $(16,17)$. However, it is still largely unclear how anticancer drugs and ROS induce apoptosis of scirrhous gastric cancer cells.

In the present study, we aimed to develop new therapeutic approaches based on the characteristic biological features 
of scirrhous cancer cells by investigating the mechanisms underlying the cytotoxicity of 5-FU, ADR, CPT-11 and ROS towards the scirrhous cancer cell line, HSC-39, in vitro.

\section{Materials and methods}

Reagents. 5-FU, ADR and CPT-11 were obtained from Sigma-Aldrich (St. Louis, MO, USA). Cisplatin (CDDP) was obtained from Nichi-Iko (Toyama, Japan), and peroxynitrite and NOC-18 were obtained from Dojindo (Kumamoto, Japan). $\mathrm{H}_{2} \mathrm{O}_{2}$ and $\mathrm{HClO}$ were purchased from Wako Pure Chemicals (Osaka, Japan). Primary antibodies, including rabbit anti-caspase-3, anti-cleaved caspase-3, anti-caspase-7 and anti-cleaved caspase-7, and secondary anti-rabbit immunoglobulin $\mathrm{G}$ ( $\mathrm{IgG}$ ) antibody conjugated to horseradish peroxidase (HRP), were purchased from Cell Signaling Technology (Danvers, MA, USA).

Cell culture. The human scirrhous gastric cancer cell line HSC-39 was derived from the peritoneal ascites of a 54-year-old male patient with scirrhous gastric cancer (10). The cells were routinely maintained in Dulbecco's modified Eagle's medium (DMEM; Gibco, Grand Island, NY, USA) supplemented with $10 \%$ heat-inactivated fetal bovine serum (FBS), $50 \mu \mathrm{g} / \mathrm{ml}$ streptomycin sulfate and $50 \mathrm{U} / \mathrm{ml}$ penicillin $\mathrm{G}$ sodium (Nacalai Tesque, Kyoto, Japan). Media and sera were obtained from Gibco. The cells were seeded at low density in 100-mm diameter dishes (Iwaki, Tokyo, Japan) or Falcon T-25 tissue culture flasks in standard medium containing $10 \%$ fetal calf serum (FCS), and incubated in $5 \% \mathrm{CO}_{2}-95 \%$ humidified air at $37^{\circ} \mathrm{C}$.

Morphological observations. Cells were observed under a phase-contrast microscope (Diamat; Nikon, Tokyo, Japan), and images were captured from random fields at a magnification of $\mathrm{x} 400$.

LDH assay for estimation of cellular cytotoxicity. The amount of lactate dehydrogenase (LDH) released into the culture medium from injured cells was used to estimate the extent of cell damage. Briefly, HSC-39 cells were seeded at $4 \times 10^{5}$ cells $/ \mathrm{ml}$ into a 48 -well multiplate (Coaster), and treated with 5-FU, ADR or CPT-11 for $48 \mathrm{~h}$ or incubated with peroxynitrite, NOC-18, $\mathrm{H}_{2} \mathrm{O}_{2}$ or $\mathrm{HClO}$ for $18 \mathrm{~h}$. The supernatants were collected and assayed for $\mathrm{LDH}$ using an LDH-Cytotoxic Test wako (Wako Pure Chemical Industries, Ltd., Osaka, Japan), according to the manufacturer's protocol. Results are expressed as percentage release according to the formula below. Total activity was obtained by treatment of the same number of cells with $0.1 \%$ Triton X-100 (Sigma-Aldrich) only, and background release of LDH was determined by collecting the culture supernatant at time 0 of incubation.

$\%$ of Release $=\{($ Experimental release $)-(0$ time release $) /$ $\{($ Total release $)$ - $(0$ time release $)\} \times 100$

MTT assay for estimation of cell viability. An MTT assay was performed using a CellTiter 96 kit (Promega, Madison, WI, USA) to evaluate the number of viable cells and the cellular metabolic activity. Briefly, $2 \times 10^{4}$ cells $/ 0.1 \mathrm{ml} /$ well were seeded onto 96 -well clustered plates (96-well plates), and incubated at $37^{\circ} \mathrm{C}$ for $72 \mathrm{~h}$ in the presence or absence of various concentrations of 5-FU, ADR or CPT-11. Then, $100 \mu 1$ of WST-1 solution (Cell Proliferation Reagent WST-1; Roche Diagnostics, Indianapolis, IN, USA) was added to each well, and the cells were incubated at $37^{\circ} \mathrm{C}$ for $1 \mathrm{~h}$. The absorbance at $450 / 630 \mathrm{~nm}$ was measured with a micro-ELISA reader (Bio-Rad, Hercules, CA, USA). Background activity, containing culture medium only, was also measured for each plate for subtraction of the background signal. Cell viability was estimated by the following formula:

$\%$ of Viability $=\{($ Experimental activity $)-($ Background activity $) /$ (Control activity without drug) - (Background activity)\} x 100

Flow cytometry. For flow cytometric analysis, HSC-39 cells were seeded at $1 \times 10^{6}$ cells $/ \mathrm{ml} / \mathrm{dish}$ (Corning Inc., Corning, NY, USA), and treated with 5-FU, ADR or CPT-11 for 20-24 h, or with peroxynitite, $\mathrm{NOC}-18, \mathrm{H}_{2} \mathrm{O}_{2}$ or $\mathrm{HClO}$ for $18 \mathrm{~h}$ at $37^{\circ} \mathrm{C}$. The cells were collected into a $5-\mathrm{ml}$ tube (Corning Falcon) and washed once with phosphate-buffered saline [PBS(-)] before the reagents of an apoptosis kit Annexin V-FITC kit $\left(\mathrm{MEBCYTO}^{\circledR}\right.$; MBL, Nagoya, Japan) were added to detect early-stage apoptotic cells. Cells were suspended in Annexin V-FITC and propidium iodide (PI), and incubated at room temperature for $15 \mathrm{~min}$ in the dark. The cells were then mixed well with fluorescence-activated cell sorting (FACS) buffer (PBS containing $0.1 \%$ bovine serum albumin and $0.1 \%$ sodium azide), filtered through a 200-mesh nylon cloth, and analyzed by a cell sorter (FACSAria III; BD Biosciences, San Jose, CA, USA). Signals from Annexin V-FITC were detected by the FITC channel (BP530/30 filter), and that from PI by the PerCP-Cy5.5 channel (BP695/40 filter); data were processed with BD FACSDiva software (BD Biosciences).

SDS-PAGE and western blot analysis. HSC-39 cells were seeded at $1 \times 10^{6}$ cells/60-mm dish (\#3000-035; Iwaki) and treated with either CPT-11 and incubated for $4 \mathrm{~h}$ or 5 -FU and ADR for $24 \mathrm{~h}$ at $37^{\circ} \mathrm{C}$. The cells were chilled on ice and washed twice with PBS by centrifugation at $4^{\circ} \mathrm{C}$ at $200 \mathrm{x}$ g for $10 \mathrm{~min}$. The final cell pellets were suspended in $100 \mu \mathrm{l}$ of lysis buffer comprised of $10 \mathrm{mM}$ EDTA (pH 8.0), 0.5\% Triton X-100 and $10 \mathrm{mM}$ Tris- $\mathrm{HCl}$ buffer ( $\mathrm{pH}$ 7.4). After standing on ice for $10 \mathrm{~min}$, the cells were centrifuged at $4^{\circ} \mathrm{C}$ at $11,000 \mathrm{x} \mathrm{g}$ for $5 \mathrm{~min}$ and the resultant supernatants were used as cell extracts.

SDS-PAGE/western blotting was performed as previously described (18). Briefly, 15- $\mu \mathrm{g}$ aliquots of cell extract were electrophoresed through a 5-20\% gradient polyacrylamide gel (ATTO, Tokyo, Japan), and the proteins were transferred to Immobilon ${ }^{\circledR}$-P polyvinylidene difluoride (PVDF) membranes (Merck Millipore, Billerica, MA, USA) for western blotting. The membranes were blocked with $30 \mathrm{mg} / \mathrm{ml}$ milk casein (MEGMILK SNOW BRAND Co., Ltd., Tokyo, Japan) in a rinse buffer comprised of $0.1 \%$ Triton X-100, $0.1 \mathrm{mM}$ EDTA and $0.8 \% \mathrm{NaCl}$ in $10 \mathrm{mM}$ Tris- $\mathrm{HCl}$ buffer, $\mathrm{pH} 7.4$, and then incubated with rabbit anti-caspase-3 or anti-caspase-7 antibodies (Cell Signaling Technology) at $4^{\circ} \mathrm{C}$ overnight. The blots were reacted with primary antibodies: anti-caspase-3 $(1: 1,000)$, anti-cleaved caspase-3 $(1: 1,000)$, anti-caspase-7 $(1: 1,000)$ or anti-cleaved caspase-7 $(1: 1,000)$, followed by reaction with 


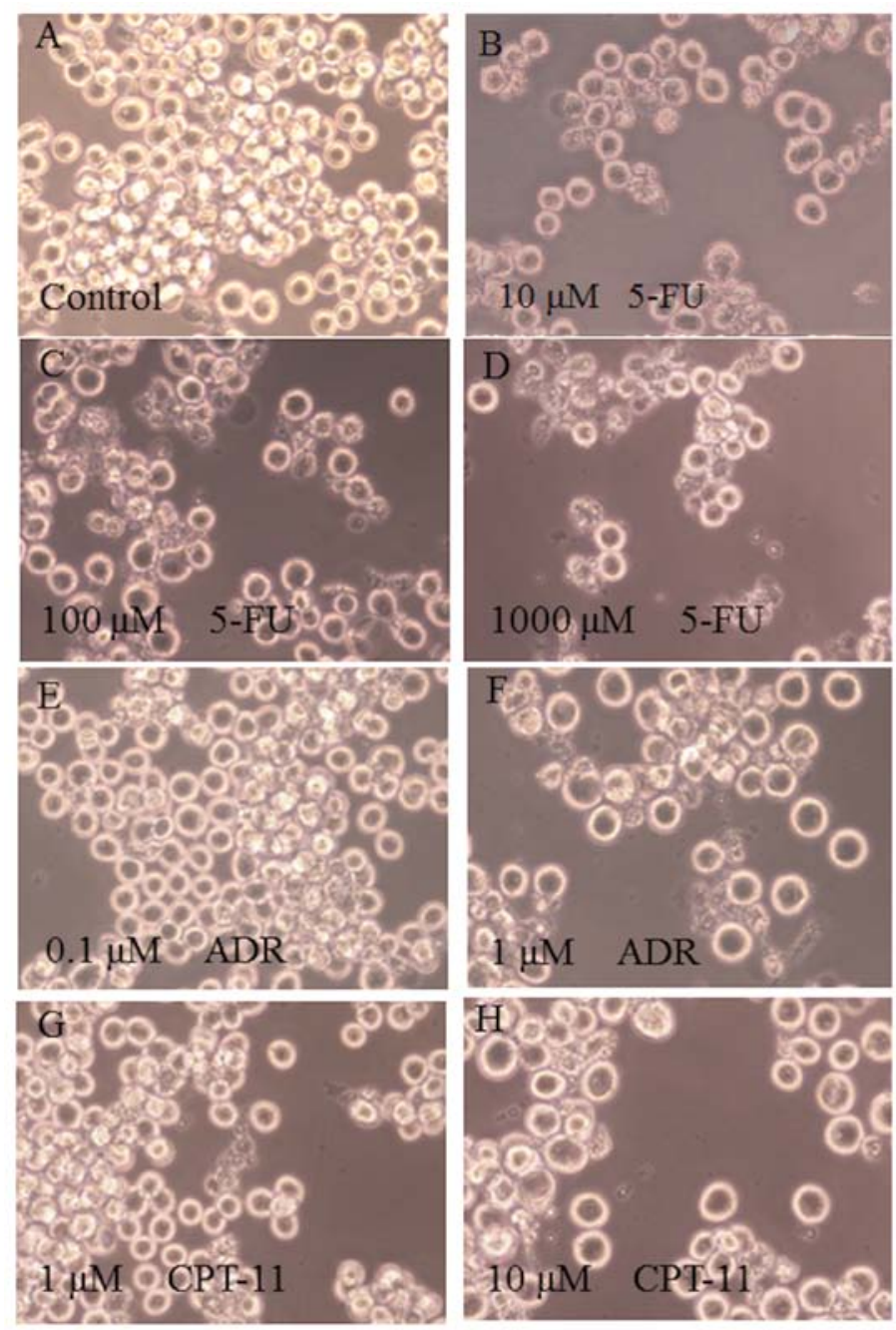

Figure 1. Morphological changes in HSC-39 cells affected by 5-fluorouracil (5-FU), adriamycin (ADR) or irinotecan (CPT-11). Cell damage in HSC-39. (A) No treatment control, (B) $10 \mu \mathrm{M}$ of 5-FU, (C) $100 \mu \mathrm{M}$ of 5-FU and (D) $1,000 \mu \mathrm{M}$ of 5-FU, (E) $0.1 \mu \mathrm{M}$ of ADR and (F) $1 \mu \mathrm{M}$ of ADR, (G) $1 \mu \mathrm{M}$ of CPT-11 and (H) $10 \mu \mathrm{M}$ of CPT-11. Cell damage was evident after treatment with 5-FU at all doses (B-D), and higher doses of ADR (F) and CPT-11 (G and H). Original magnification, $\mathrm{x} 400$.

a secondary anti-rabbit IgG antibody conjugated to HRP $(1: 1,000)$. Chemiluminescence was generated using Pierce ECL Western Blotting Substrate (Thermo Fisher Scientific, Inc., Waltham, MA, USA), and detected using a LAS 3000 Mini Image Analyzer (FujiFilm, Tokyo, Japan). The intensity of each band was analyzed and quantitated using Image J software (ver. $1.48 \mathrm{~V})$.

Statistical analysis. Results are shown as the mean \pm standard error of the mean (SEM) for at least 3 experiments performed independently using separate cell preparations. Significant differences between two groups were analyzed using Student's $\mathrm{t}$-test and were considered statistically significant at $\mathrm{P}<0.05$.

\section{Results}

Morphological changes in HSC-39 cells treated with chemotherapeutic reagents. The morphology of HSC-39 cells was observed under a phase-contrast microscope after treatment with the anticancer reagents. The addition of $100 \mu \mathrm{M}$ of 5-FU (Fig. 1C) induced the most marked changes in the cells, such as agglutination and cell membrane rupture, while treatment with $10 \mu \mathrm{M}$ of 5-FU (Fig. 1B) induced no marked changes. When treated with $1 \mu \mathrm{M}$ of ADR (Fig. 1F) or $10 \mu \mathrm{M}$ of CPT-11 (Fig. 1H), the number of intact and apoptotic cells were both decreased. Fragmentation of cells was also frequently observed after treatment with $100 \mu \mathrm{M}$ of CPT-11 (data not shown). These results suggest that treatment of HSC-39 cells with the anticancer reagents led to a decrease in the number of living cells with a concomitant increase in either apoptotic cells when treated with 5-FU or aponecrotic cells when treated with ADR and CPT-11.

Cytotoxic effects of chemotherapeutic agents on HSC-39 cells. Apoptotic stimuli induce necrosis of cells through depletion of cellular ATP. The type of cell death varies depending on the mechanisms and processes that lead to these responses in cells and tissues (19). LDH release from cells principally results from rupture of the cell membrane. Fig. 2, LDH was significantly released from the cells after treatment with 5-FU at $10 \mathrm{mM}$ or higher in a dose-dependent manner (Fig. 2A). In contrast, significant release of LDH was predominantly observed with treatment at high concentrations of ADR at $(10 \mu \mathrm{M}$; Fig. 2B) and CPT-11 (100 $\mu \mathrm{M}$; Fig. 2C). 

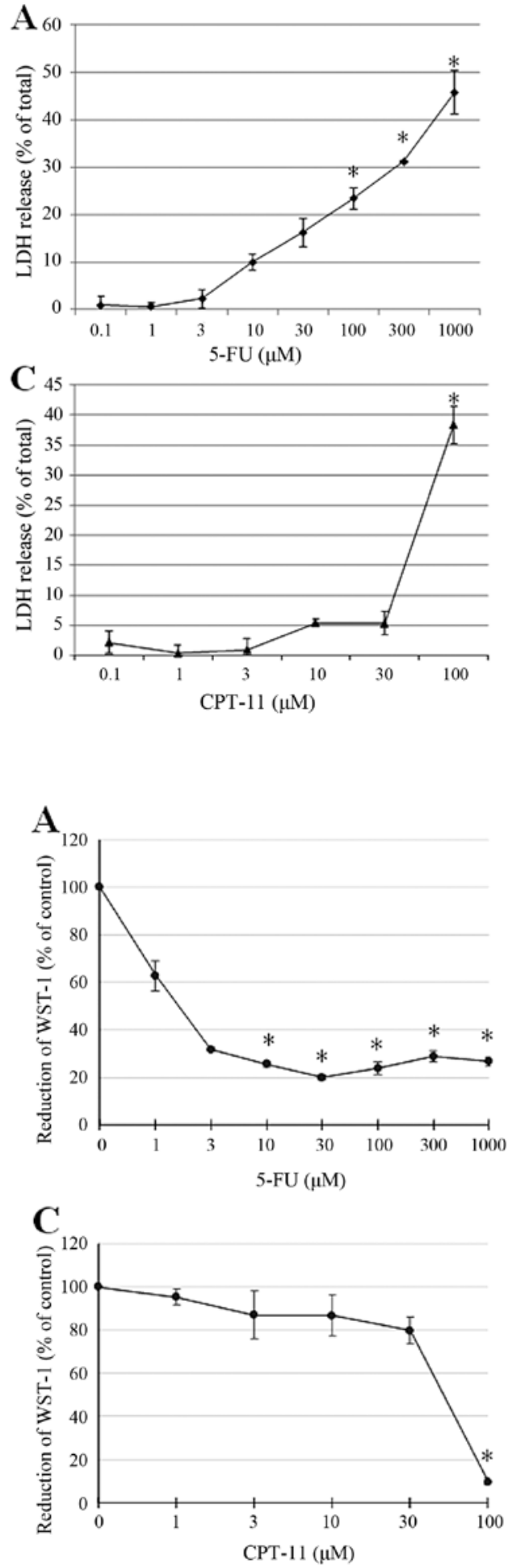

Similarly, viability, as estimated by the MTT assay using WST-1 as a substrate, differed between treatment groups. 5-FU at $1 \mathrm{mM}$ attenuated WST-1 reduction, which was more pronounced and significant at higher doses (Fig. 3A). In contrast, ADR and CPT-11, which exerted similar effects on cell viability, only significantly attenuated WST-1 reduction at 10 and $100 \mu \mathrm{M}$, respectively (Fig. 3B and C). These results showed that the effect of 5-FU treatment on cell damage and decrease in cell viability as measured by LDH release and MTT assay was different compared to that for ADR or CPT-11. This suggests that 5-FU may induce cell damage via a

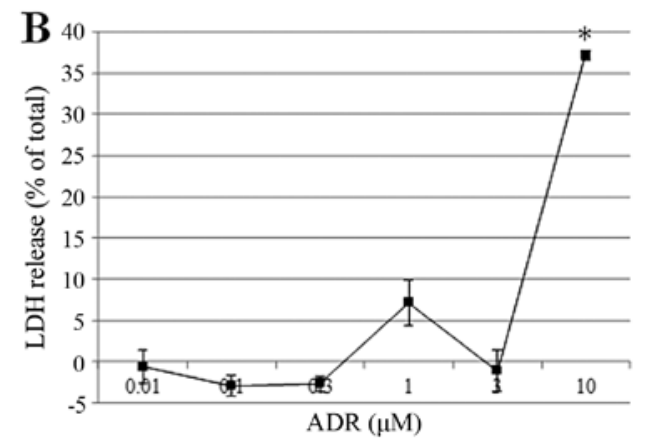

Figure 2. LDH release from HSC-39 cells treated with 5-FU, ADR and CPT-11. LDH release was examined as a marker of cell damage of HSC-39 cells after treatment with increasing concentrations of (A) 5-FU, (B) ADR or (C) CPT-11. LDH was released in a dose-dependent manner in cells treated with (A) 5-FU. In contrast, LDH release was predominantly observed at high doses of (B) ADR and (C) CPT-11. Results indicate the mean \pm standard error of the mean (SEM) for 3 independent experiments; ${ }^{*} \mathrm{P}<0.05$ between $0 \mathrm{mM}$ and each sample. LDH, lactate dehydrogenase; 5-FU, 5-fluorouracil; ADR, adriamycin; CPT-11, irinotecan.

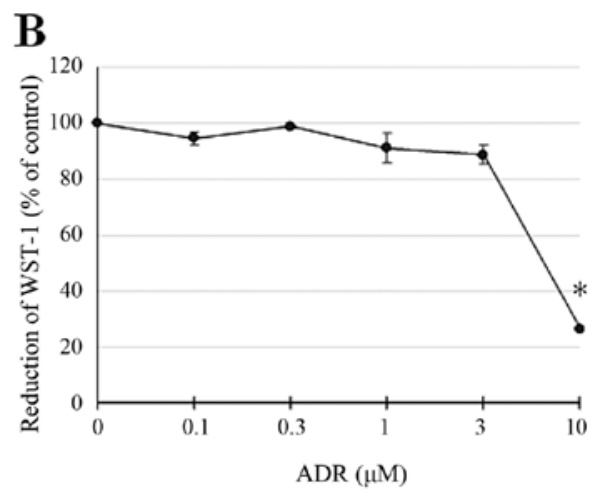

Figure 3. Viability of HSC-39 cells treated with 5-FU, ADR and CPT-11. Viability of HSC-39 cells treated with increasing doses of (A) 5-FU, (B) ADR or (C) CPT-11 using the MTT assay, and WST-1 as a substrate. (A) 5-FU inhibited cell viability at all doses tested, while (B) ADR and (C) CPT-11 predominantly inhibited cell viability at high doses. The results are shown as WST-1 decrease relative to the no treatment control. Data indicate the mean \pm SEM for 3 independent experiments; ${ }^{*} \mathrm{P}<0.05$ between the nontreated control and each sample. 5-FU, 5-fluorouracil; ADR, adriamycin; CPT-11, irinotecan.

different mechanism than cell membrane disruption for LDH release, indicating different functions in apoptotic cell death.

Induction of apoptosis and/or necrosis in HSC-39 cells. To examine apoptotic cell death, we examined cell-surface binding of Annexin V, a phosphatidylserine (PS)-binding protein, and staining of cells with PI by flow cytometric analysis. Translocation of PS to the external cell surface is not unique to apoptosis; it also occurs during cell necrosis. The difference between apoptosis and necrosis is in cell membrane integrity: during the initial stages of apoptosis 


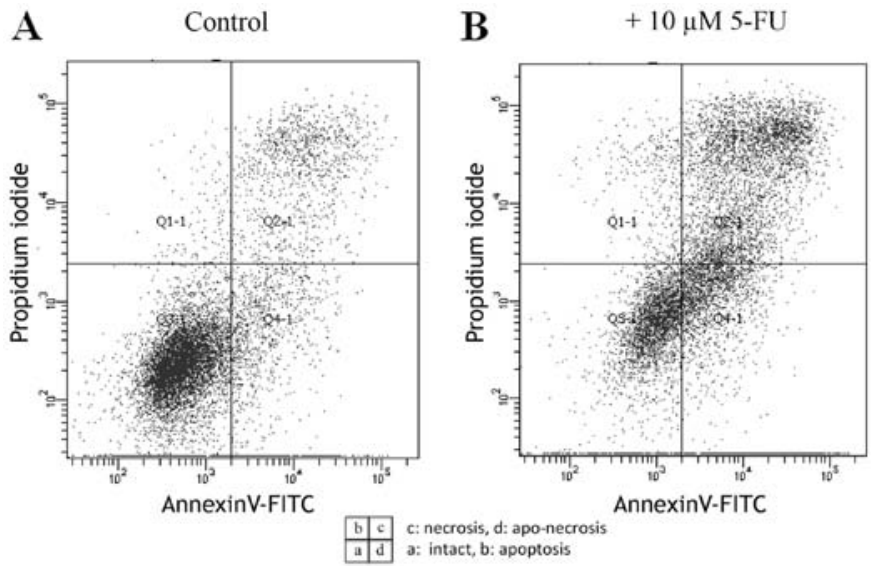

Figure 4. Induction of apoptosis and/or necrosis in HSC-39 cells treated with 5-FU. Annexin V/PI fluorescent signals in HSC-39 cells incubated (A) without or (B) with $10 \mu \mathrm{M}$ of 5-FU. Fluorescent signals in HSC-39 cells indicate the population of cells positive for Annexin V, and the ordinate indicates the population of cells positive for PI. As shown in the insert, area c, corresponds to intact cells; d, apoptotic cells; a, necrotic cells; and b, aponecrotic cells. 5-FU, 5-fluorouracil, PI, propidium iodide.

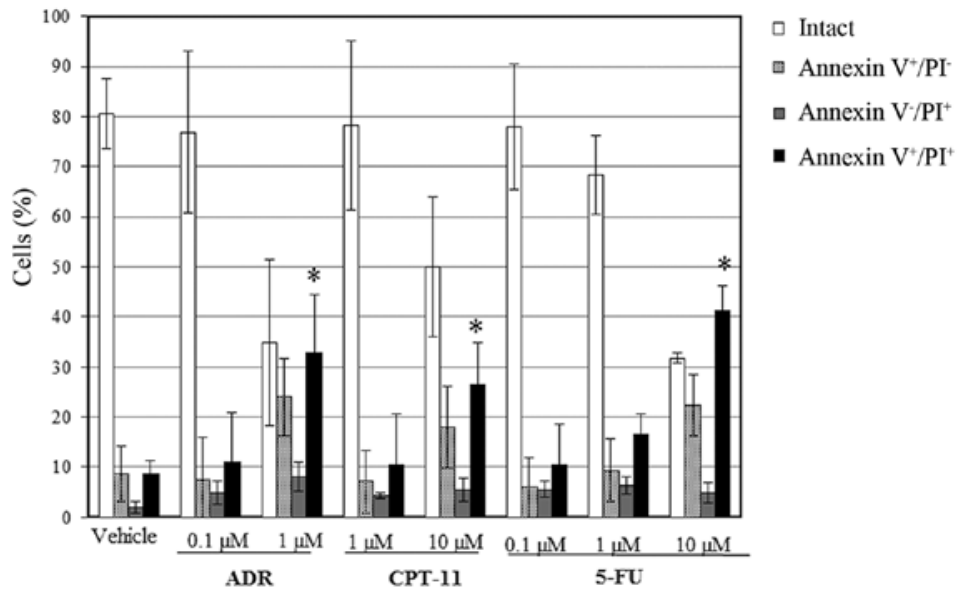

Figure 5. Induction of apoptosis and/or necrosis in HSC-39 cells treated with 5-FU, ADR or CPT-11. Annexin V/PI staining in HSC-39 cells treated with various concentrations of 5-FU, ADR or CPT-11. Treatment with high doses of all 3 treatments led to decreased intact cells and increased Annexin $\mathrm{V}^{+} / \mathrm{PI}^{-}$and Annexin $\mathrm{V}^{+} / \mathrm{PI}^{+}$cells. The results are expressed as the mean \pm SEM for 3 independent experiments; ${ }^{*} \mathrm{P}<0.05$ between the non-treated control and each sample. 5-FU, 5-fluorouracil; ADR, adriamycin; CPT-11, irinotecan; PI, propidium iodide.

the cell membrane remains intact, but for necrosis, the cell membrane becomes leaky, allowing access to PI to stain nucleic acids. The Annexin V assay allows for the detection of the early phase of apoptosis, before the loss of cell membrane integrity, and permits assessment of apoptotic death. As shown in Fig. 4A, the control cells showed no fluorescein staining. In contrast, cells treated with $10 \mu \mathrm{M}$ of 5 -FU for $48 \mathrm{~h}$ displayed significant binding of Annexin V-fluorescein to the membrane surface (Fig. 4B), indicating apoptosis. To distinguish between apoptotic and potential necrotic or lysed cells that may also have been exposed to PS due to loss of membrane integrity, we concomitantly examined Annexin $\mathrm{V}^{+}$and $\mathrm{PI}^{+}$cells, which correspond to aponecrotic HSC-39 cells (Fig. 4B). Annexin $\mathrm{V}^{+}$ and $\mathrm{PI}^{+}$cells were also observed after treatment with $1 \mu \mathrm{M}$ of ADR and $10 \mu \mathrm{M}$ of CPT-11, suggesting that these drugs induced apoptosis and aponecrosis (Fig. 5).

Caspase-7 mediates apoptosis in HSC-39 cells. Caspase family members play important roles in the progression of apoptosis in various cells. Among them, caspase- 3 and -7 are

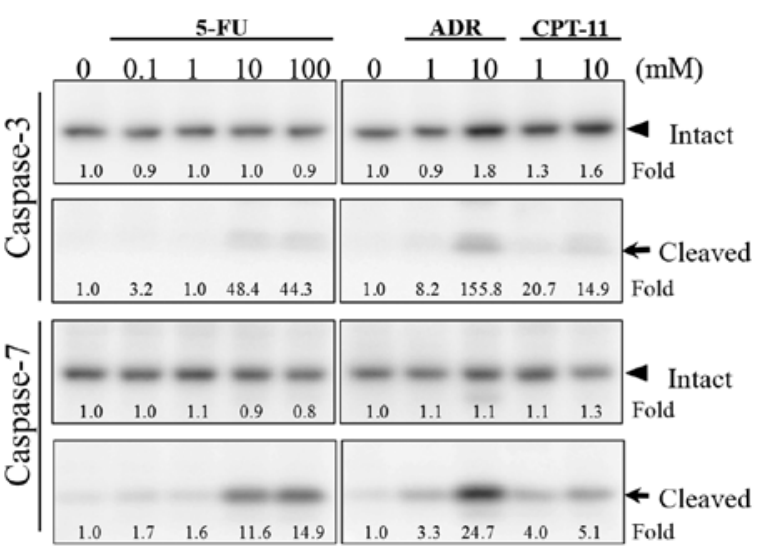

Figure 6. Activation of caspase-7 and -3 in HSC-39 cells treated with 5-FU, ADR or CPT-11. Extracts of HSC-39 cells treated with increasing concentrations of 5-FU, ADR or CPT-11 subjected to SDS-PAGE/western blotting. The activation of caspase-7, but not caspase- 3 was cleaved in treated cells. The intensity of each band was quantitated by image analysis as described in the text, and the relative fold to the corresponding untreated control was shown at the bottom of the individual figure. 5-FU, 5-fluorouracil; ADR, adriamycin; CPT-11, irinotecan. 

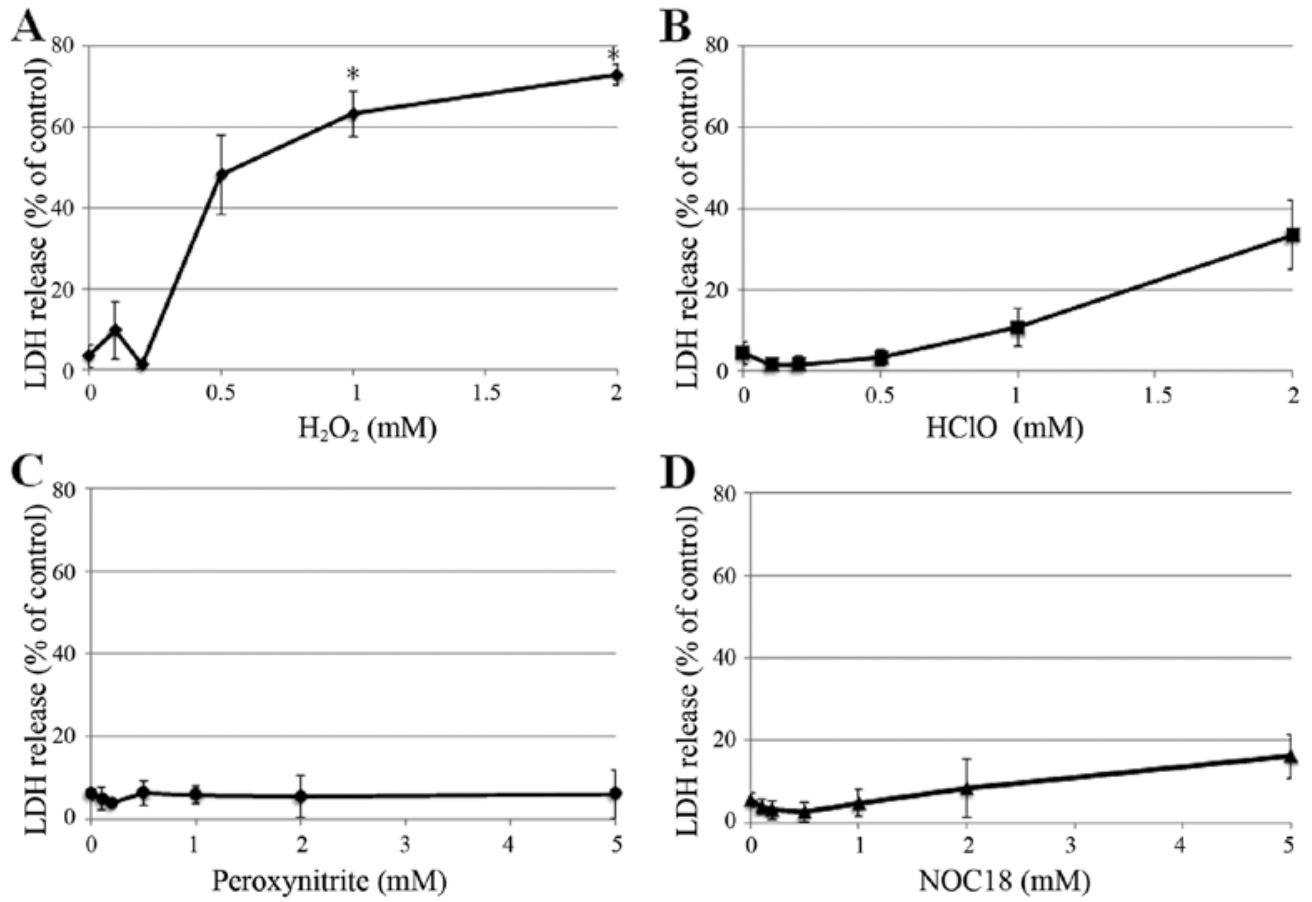

Figure 7. Cytotoxic effects of ROS on HSC-39 cells monitored by LDH release in HSC-39 cells treated with various concentrations of ROS, including (A) $\mathrm{H}_{2} \mathrm{O}_{2}$, (B) $\mathrm{HClO}$, (C) peroxynitrite and (D) NOC-18. Cell death was quantified using the LDH release assay. (A) $\mathrm{H}_{2} \mathrm{O}_{2}$ induced significant LDH release at all concentrations. (B) $\mathrm{HClO}$ and (D) NOC-18 induced low levels of $\mathrm{LDH}$ release, while (C) peroxynitrite had no effect. The results are expressed as the mean \pm SEM for $>3$ independent experiments; ${ }^{*} \mathrm{P}<0.05$ between $0 \mathrm{mM}$ and each sample. ROS, reactive oxygen species; $\mathrm{LDH}$, lactate dehydrogenase.
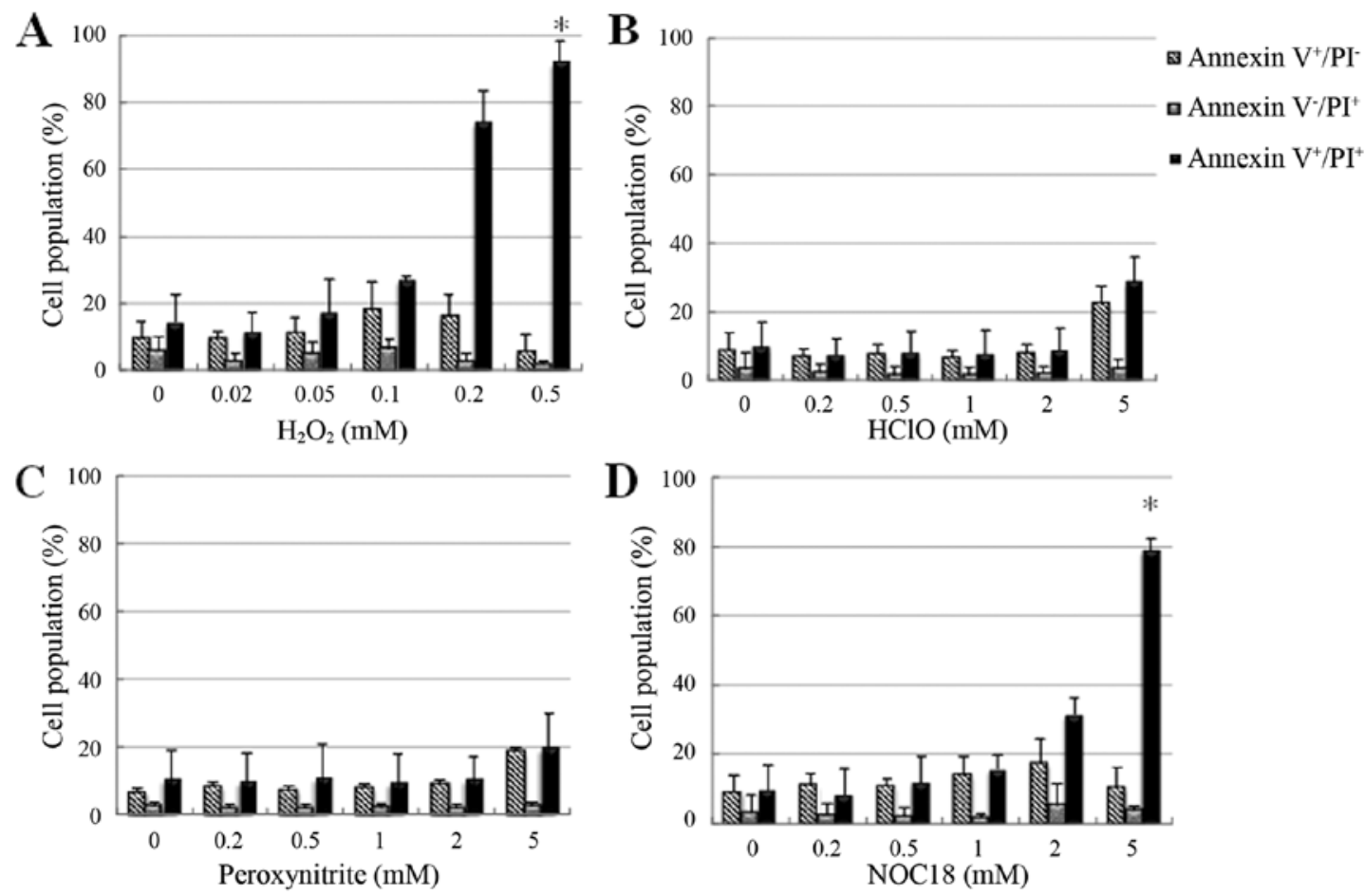

Figure 8. Induction of apoptosis and/or necrosis of HSC-39 cells by ROS. Annexin V/PI signals in HSC-39 cells treated with various concentrations of (A) $\mathrm{H}_{2} \mathrm{O}_{2}$, (B) $\mathrm{HClO}$, (C) peroxynitrite or (D) NOC-18. Treatment with high doses of (A) $\mathrm{H}_{2} \mathrm{O}_{2}$ and (D) NOC-18 led to significant increases in Annexin $\mathrm{V}^{+} / \mathrm{PI}^{+}$ cells, while treatment with (B) $\mathrm{HClO}$ led to increases in Annexin $\mathrm{V}^{+} / \mathrm{PI}^{-}$and Annexin $\mathrm{V}^{+} / \mathrm{PI}^{+}$cells. (C) Treatment with peroxynitrite had no effect. The results are expressed as the mean \pm SD for independent 3 experiments; ${ }^{*} \mathrm{P}<0.05$ between the non-treated control and each sample. ROS, reactive oxygen species; PI, propidium iodide.

the effector caspases activated by apical caspase and cleavage of cellular death substrates. Therefore, we examined which caspase was involved in the induction of cytotoxicity. The level of cleaved caspase-7, an activated form, was much higher than 
that of the cleaved caspase- 3 after treatment with $10-100 \mu \mathrm{M}$ of 5-FU for $48 \mathrm{~h}$ compared to the control (Fig. 6). Similar results were obtained with treatment at $1-10 \mu \mathrm{M}$ of ADR or CPT-11. These results suggest that caspase-7 is responsible for the progression of apoptosis of HSC-39 cells induced by these chemotherapeutic drugs.

Cytotoxic effects and induction of apoptosis of HSC-39 cells by ROS. ROS have been shown to induce apoptosis in many different cell systems (20). In the present study, we examined the cytotoxic effects of ROS on HSC-39 cells. HSC-39 cells released amounts of LDH upon treatment with $0.5 \mathrm{mM}$ or higher of $\mathrm{H}_{2} \mathrm{O}_{2}$, with $>60 \%$ release significantly occurring at $1 \mathrm{mM}$ and greater (Fig. 7A). In contrast, HSC-39 cells showed less sensitivity to $\mathrm{HClO}$ (Fig. 7B) and NOC-18 (Fig. 7D). Little to no LDH release was induced by peroxynitrite (Fig. 7C).

We next examined the induction of apoptosis and/or necrosis of HSC-39 cells by Annexin V and PI staining and flow cytometric analysis. Treatment with $0.1 \mathrm{mM} \mathrm{H}_{2} \mathrm{O}_{2}$ induced Annexin $\mathrm{V}^{+}$and $\mathrm{PI}^{-}$cells, indicating early stage apoptosis, while treatment with $0.2-0.5 \mathrm{mM} \mathrm{H}_{2} \mathrm{O}_{2}$ or $2-5 \mathrm{mM}$ NOC-18 induced Annexin $\mathrm{V}^{+}$and $\mathrm{PI}^{+}$cells, indicating necrosis or aponecrosis, in a dose-dependent manner. HSC-39 cells showed high sensitivity to $\mathrm{H}_{2} \mathrm{O}_{2}$ and NOC-18. These were significant differences compared with the controls. At low doses, $\mathrm{HClO}$ had no effect on the cell membrane, but at high doses $(5 \mathrm{mM})$ induced Annexin $\mathrm{V}^{+}$and $\mathrm{PI}^{-}$cells and Annexin $\mathrm{V}^{+}$ and $\mathrm{PI}^{+}$cells, indicating the induction of apoptosis and aponecrosis (Fig. 8A and B). Similarly, the cells were induced after treatment with peroxynitrite (Fig. 8C). In addition, the pattern of cytotoxicity appeared to change over time in all treatment groups, suggesting that induction of apoptosis occurs first, followed by necrosis. However, treatment with $\mathrm{H}_{2} \mathrm{O}_{2}$ or $\mathrm{HClO}$ did not result in typical apoptosis (data not shown).

These results suggest that HSC-39 cells showed high dose-dependent sensitivity to $\mathrm{H}_{2} \mathrm{O}_{2}$ and NOC-18, but low sensitivity to $\mathrm{HClO}$ and peroxynitrite, suggesting that the cell damage may be linked to the degree of membrane permeability induced by the various ROS.

\section{Discussion}

In the present study, we examined the mechanisms underlying the cytotoxicity of anticancer drugs and reactive oxygen species (ROS) toward a human scirrhous cancer cell line, HSC-39, in vitro. We demonstrated that 5-FU induced apoptosis and ADR and CPT-11 induced necrosis and/or aponecrosis of the HSC-39 cells. 5-FU inhibited cell viability and induced little LDH release at low doses, while ADR and CPT-11 inhibited cell viability and induced LDH release at high doses. Our findings suggest that $5-\mathrm{FU}$ is a reasonable chemotherapeutic drug for scirrhous gastric cancer. In phase II trials, the 5-FU analog S-1 showed a 33\% response rate against scirrhous gastric cancer. Due to the reported promising effects of S-1 for neoadjuvant chemotherapy against scirrhous gastric cancer in a pilot study, a new phase II trial was planned to determine the survival benefit of $\mathrm{S}-1$ treatment (21).

Apoptosis is a crucial mechanism for many biological processes. The apoptotic process is characterized by distinct morphological features. In HSC-39 cells, typical structural changes and related alterations in cell function of the apoptotic pathway were observed, including cell rupture, translocation of PS to the outer layer of the plasma membrane, and altered mitochondrial metabolic activity.

Several chemotherapeutic drugs have been evaluated for their antitumor function. Compared with the best supportive care, the survival benefit of 5-FU has been reported based on chemotherapy for metastatic gastric cancer (22). In the present study, 5-FU, ADR and CPT-11 induced apoptosis and/or aponecrosis in HSC-39 cells in a dose-dependent manner, as assessed by FACScan analysis (Figs. 4 and 5). 5-FU effectively inhibited WST-1 decrease even at low doses where little LDH release was observed, whereas ADR and CPT-11 inhibited WST-1 decrease only at high doses where LDH release occurred (Figs. 2A and 3A). A previous study indicated that administration of 5-FU results in an increase in the $\mathrm{S}$ phase fraction in human gastric carcinoma, which is coincidental with the appearance of apoptosis-positive cells (23). Moreover, thymidylate synthase (TS) activity is immediately markedly suppressed. These findings suggest that induction of apoptosis and inhibition of DNA synthesis, both induced by 5-FU, may be closely associated with its antitumor effects. At a low dose, 5-FU inhibits energy metabolism, resulting in decreased ATP levels to impair membrane barrier function, rather than inducing direct damage to cells (24). In contrast, ADR induces an increase of $c$-jun and ATF3 mRNA levels in the mitogen-activated protein kinase (MAPK) pathway, followed by apoptosis (25). This may explain why ADR predominantly induced apoptosis and LDH release in HSC-39 cells at high doses. The mechanism underlying the similar actions of CPT-11 remains unclear.

We also demonstrated that the progression of apoptosis upon treatment with 5-FU, ADR and CPT-11 was accompanied by cleavage of caspase-7, but not caspase-3 (Fig. 6). Caspase-3 normally exists in the cytosol as an inactive precursor that becomes activated through cleavage in apoptotic cells (26). Caspase-7, but not caspase-3, undergoes proteolytic activation during lovastatin-induced apoptosis, an effect prevented by mevalonate, and was identified as a possible mediator of lovastatin-induced apoptosis (27). The activation of caspase-7 during the apoptosis of HSC-39 cells (Fig. 6) demonstrated in the present study, may indicate a new pathway in the apoptotic cascade in scirrhous gastric cancer cells.

HSC-39 cells also showed high sensitivity to $\mathrm{H}_{2} \mathrm{O}_{2}$ (Fig. 7A), as indicated by LDH release and Annexin V and PI staining. $\mathrm{H}_{2} \mathrm{O}_{2}$ has strong intracellular cytotoxic effects due to its high membrane permeability. Furthermore, $\mathrm{H}_{2} \mathrm{O}_{2}$ can induce apoptosis in neutrophils; this can be prevented by catalase, an enzyme that also prevents spontaneous neutrophil apoptosis. This suggests that $\mathrm{H}_{2} \mathrm{O}_{2}$ may be an important triggering mechanism responsible for the short life-span of mature neutrophils. Caspase-3, but not other caspases, is required for commitment to ROS-induced apoptosis (28).

The susceptibility of HSC-39 cells to 5-FU and $\mathrm{H}_{2} \mathrm{O}_{2}$ suggests that there may be common mechanisms underlying the cytotoxicity of these reagents. Manganese superoxide dismutase (Mn-SOD) negatively regulates 5-FU-mediated apoptosis induction in squamous carcinoma cells (29), and 5-FU increases cellular accumulation of $\mathrm{H}_{2} \mathrm{O}_{2}$ in $\mathrm{CT} 26$ colon cancer cells (30). These studies suggest that 5 -FU induces increases in cellular $\mathrm{H}_{2} \mathrm{O}_{2}$ levels, which may lead to decreased metabolic 
activity, as indicated by the WST-1 assay (Fig. 3A), and increased apoptotic and subsequent necrotic changes (Fig. 5), as well as increased LDH release (Fig. 2A) in HSC-39 cells as observed in the present study.

HSC-39 cells undergo apoptosis when treated with TGF- $\beta$ under serum-free culture conditions, which is mediated by activation of an apoptosis signal transduction pathway $(31,32)$. Recent findings showed that 5-FU treatment activated the TGF- $\beta$ pathway in drug resistant colorectal carcinoma cells in an in vivo and in vitro model (33). Liu and Desai reported that TGF- $\beta 1$ increased ROS production and suppressed antioxidant enzymes, leading to a redox imbalance. Therapeutic targeting of TGF- $\beta$-induced and ROS-dependent cellular signaling represents a novel approach in the treatment of fibrotic disorders (34). Therefore, it may be of interest to examine the interaction between HSC-39 and TGF- $\beta$-producing cells such as activated fibroblasts or macrophages for peritoneal metastasis. Furthermore, it may be beneficial to examine whether various cytokines act as transcriptional regulators in TGF- $\beta$-mediated apoptosis. We are now in the process of investigating this point. Several studies provided evidence supporting the involvement of ROS in the induction of apoptosis and demonstrated the importance of ROS in the release of cytochrome $c$ from the mitochondria. 5-FU-induced autophagy may function as a resistance mechanism against apoptotic cell death (35). It may provide a novel strategy to overcome therapy resistance.

Cisplatin (cis-diamminedichloroplatinum) was developed by Rosenberg (36) in the 1960s and was initially used in the treatment of head and neck, uterine and bladder cancers (37). Cisplatin is one of the most important drugs for the treatment of gastric cancer; it has demonstrated a high positive-response rate in the treatment of gastric cancer. Although, combination treatment of 5-FU and cisplatin has demonstrated a significantly increased cancer-free survival compared to treatment with 5-FU alone, no significant differences have been observed in overall survival rate between the two treatments (38). This survival difference, however, may result from chance in conducting the subgroup analysis and may have limited influence on the interpretation of the primary conclusion of the study.

In conclusion, we demonstrated that 5-FU induces apoptosis of HSC-39 cells, inhibits cell viability and induces little LDH release at low doses. In contrast, ADR and CPT-11 induce necrosis and/or aponecrosis of HSC-39 cells, inhibit cell viability and induce LDH release at high doses. The present study provides important insights into the underlying mechanisms of apoptosis behind the cytotoxicity for scirrhous gastric cancer. Furthermore, consistent with the widening acceptance of combination chemotherapies in clinical practice, such as with fluoropyrimidine agents, cisplatin, irinotecan and taxanes, our findings suggest that 5-FU has potential efficacy and that the use of 5-FU in combination with other chemotherapeutic agents that attack the membrane barrier may be a successful chemotherapy regimen for scirrhous gastric cancer.

\section{References}

1. Ikeguchi M, Miyake T, Matsunaga T, Yamamoto M, Fukumoto Y, Yamada Y, Fukuda K, Saito H, Tatebe S and Tsujitani S: Recent results of therapy for scirrhous gastric cancer. Surg Today 39: 290-294, 2009
2. Hippo Y, Yashiro M, Ishii M, Taniguchi H, Tsutsumi S, Hirakawa K, Kodama T and Aburatani H: Differential gene expression profiles of scirrhous gastric cancer cells with high metastatic potential to peritoneum or lymph nodes. Cancer Res 61: 889-895, 2001.

3. Kitamura K, Beppu R, Anai H, Ikejiri K, Yakabe S, Sugimachi K and Saku M: Clinicopathologic study of patients with Borrmann type IV gastric carcinoma. J Surg Oncol 58: 112-117, 1995.

4. Nakamura R, Saikawa Y, Wada N, Yoshida M, Kubota T, Kumai K and Kitajima M: Retrospective analysis of prognosis for scirrhous-type gastric cancer: One institution's experience. Int J Clin Oncol 12: 291-294, 2007.

5. Ohtsu A, Boku N, Yoshida S, Miyata Y, Shirao K, Shimada Y and Kurihara M; Japan Clinical Oncology Group: Response of the primary lesion in gastric cancer to chemotherapeutic trials. Int J Clin Onco1 3: 3-6, 1998.

6. Koizumi W, Narahara H, Hara T, Takagane A, Akiya T, Takagi M, Miyashita K, Nishizaki T, Kobayashi O, Takiyama W, et al: S-1 plus cisplatin versus S-1 alone for first-line treatment of advanced gastric cancer (SPIRITS trial): A phase III trial. Lancet Oncol 9: 215-221, 2008

7. Wilke H, Muro K, Van Cutsem E, Oh SC, Bodoky G, Shimada Y, Hironaka S, Sugimoto N, Lipatov O, Kim TY, et al; RAINBOW Study Group: Ramucirumab plus paclitaxel versus placebo plus paclitaxel in patients with previously treated advanced gastric or gastro-oesophageal junction adenocarcinoma (RAINBOW): A double-blind, randomised phase 3 trial. Lancet Oncol 15: 1224-1235, 2014.

8. Fuchs CS, Tomasek J, Yong CJ, Dumitru F, Passalacqua R, Goswami C, Safran H, dos Santos LV, Aprile G, Ferry DR, et al; REGARD Trial Investigators: Ramucirumab monotherapy for previously treated advanced gastric or gastro-oesophageal junction adenocarcinoma (REGARD): An international, randomised, multicentre, placebo-controlled, phase 3 trial. Lancet 383: 31-39, 2014.

9. Nashimoto A, Akazawa K, Isobe Y, Miyashiro I, Katai H, Kodera Y, Tsujitani S, Seto Y, Furukawa H, Oda I, et al: Gastric cancer treated in 2002 in Japan: 2009 annual report of the JGCA nationwide registry. Gastric Cancer 16: 1-27, 2013.

10. Yanagihara K, Seyama T, Tsumuraya M, Kamada N and Yokoro K: Establishment and characterization of human signet ring cell gastric carcinoma cell lines with amplification of the c-myc oncogene. Cancer Res 51: 381-386, 1991.

11. Semba S, Kodama Y, Ohnuma K, Mizuuchi E, Masuda R, Yashiro M, Hirakawa K and Yokozaki H: Direct cancer-stromal interaction increases fibroblast proliferation and enhances invasive properties of scirrhous-type gastric carcinoma cells. $\mathrm{Br}$ J Cancer 101: 1365-1373, 2009.

12. Ishida M, Gomyo Y, Ohfuji S, Ikeda M, Kawasaki $\mathrm{H}$ and Ito $\mathrm{H}$ : Evidence that expression of a mutated p53 gene attenuates apoptotic cell death in human gastric intestinal-type carcinomas in vivo. Jpn J Cancer Res 88: 468-475, 1997.

13. Boku N, Yamamoto S, Shirao K, Doi T, Sawaki A, Koizumi W, Saito H, Yamaguchi K, Kimura A, et al: Randomized phase III study of 5-fluorouracil (5-FU) alone versus combination of irinotecan and cisplatin (CP) versus $\mathrm{S}-1$ alone in advanced gastric cancer (JCOG9912). J Clin Oncol 2007 ASCO Annual Meeting Proceedings 25: LBA4513, 2007.

14. Ichikawa W and Sasaki Y: Challenges in predicting the clinical outcome in S-1-based chemotherapy for gastric cancer patients. Int J Clin Oncol 13: 206-211, 2008.

15. Shitara K, Ishiguro A, Munakata M, Wada R and Sakata Y: Retrospective analysis of stage IV advanced gastric cancer treated with S-1 or other chemotherapy. Int J Clin Oncol 11: 367-374, 2006.

16. Sato K, Akaike T, Kojima Y, Ando M, Nagao M and Maeda H: Evidence of direct generation of oxygen free radicals from heterocyclic amines by NADPH/cytochrome P-450 reductase in vitro. Jpn J Cancer Res 83: 1204-1209, 1992.

17. Lanks KW, Gao JP and Sharma T: Photodynamic enhancement of doxorubicin cytotoxicity. Cancer Chemother Pharmacol 35: 17-20, 1994.

18. Kawakami T, Kawamura K, Fujimori K, Koike A and Amano F: Influence of the culture medium on the production of nitric oxide and expression of inducible nitric oxide synthase by activated macrophages in vitro. Biochem Biophys Rep 5: 328-334, 2016.

19. Leist M, Single B, Castoldi AF, Kühnle S and Nicotera P: Intracellular adenosine triphosphate (ATP) concentration: A switch in the decision between apoptosis and necrosis. J Exp Med 185: 1481-1486, 1997. 
20. Simon HU, Haj-Yehia A and Levi-Schaffer F: Role of reactive oxygen species (ROS) in apoptosis induction. Apoptosis 5: 415-418, 2000.

21. Kinoshita T, Konishi M, Nakagohri T, Inoue K, Oda T, Takahashi S, Boku N, Ohtsu A and Yoshida S: Neoadjuvant chemotherapy with S-1 for scirrhous gastric cancer: A pilot study. Gastric Cancer 6 (Suppl 1): S40-S44, 2003.

22. Ohtsu A: Current status and future prospects of chemotherapy for metastatic gastric cancer: A review. Gastric Cancer 8: 95-102, 2005.

23. Johnstone RW, Ruefli AA and Lowe SW: Apoptosis: A link between cancer genetics and chemotherapy. Cell 108: 153-164, 2002.

24. Johnston PG, Lenz HJ, Leichman CG, Danenberg KD, Allegra CJ, Danenberg PV and Leichman L: Thymidylate synthase gene and protein expression correlate and are associated with response to 5 -fluorouracil in human colorectal and gastric tumors. Cancer Res 55: 1407-1412, 1995.

25. Yu R, Shtil AA, Tan TH, Roninson IB and Kong AN: Adriamycin activates c-jun $\mathrm{N}$-terminal kinase in human leukemia cells: A relevance to apoptosis. Cancer Lett 107: 73-81, 1996.

26. Henkels KM and Turchi JJ: Cisplatin-induced apoptosis proceeds by caspase-3-dependent and -independent pathways in cisplatin-resistant and -sensitive human ovarian cancer cell lines. Cancer Res 59: 3077-3083, 1999.

27. Marcelli M, Cunningham GR, Walkup M, He Z, Sturgis L, Kagan C, Mannucci R, Nicoletti I, Teng B and Denner L: Signaling pathway activated during apoptosis of the prostate cancer cell line LNCaP: Overexpression of caspase-7 as a new gene therapy strategy for prostate cancer. Cancer Res 59 382-390, 1999.

28. Matsura T, Kai M, Fujii Y, Ito $H$ and Yamada K: Hydrogen peroxide-induced apoptosis in HL-60 cells requires caspase-3 activation. Free Radic Res 30: 73-83, 1999.

29. Ueta E, Yoneda K, Yamamoto T and Osaki T: Manganese superoxide dismutase negatively regulates the induction of apoptosis by 5 -fluorouracil, peplomycin and gamma-rays in squamous cell carcinoma cells. Jpn J Cancer Res 90: 555-564, 1999.
30. Alexandre J, Nicco C, Chéreau C, Laurent A, Weill B, Goldwasser F and Batteux F: Improvement of the therapeutic index of anticancer drugs by the superoxide dismutase mimic mangafodipir. J Natl Cancer Inst 98: 236-244, 2006.

31. Yanagihara $\mathrm{K}$ and Tsumuraya $\mathrm{M}$ : Transforming growth factor $\beta_{1}$ induces apoptotic cell death in cultured human gastric carcinoma cells. Cancer Res 52: 4042-4045, 1992.

32. Ohta S, Yanagihara K and Nagata K: Mechanism of apoptotic cell death of human gastric carcinoma cells mediated by transforming growth factor $\beta$. Biochem J 324: 777-782, 1997.

33. Romano G, Santi L, Bianco MR, Giuffrè MR, Pettinato M, Bugarin C, Garanzini C, Savarese L, Leoni S, Cerrito MG, et al: The TGF- $\beta$ pathway is activated by 5 -fluorouracil treatment in drug resistant colorectal carcinoma cells. Oncotarget 7: 22077-22091, 2016.

34. Liu RM and Desai LP: Reciprocal regulation of TGF- $\beta$ and reactive oxygen species: A perverse cycle for fibrosis. Redox Biol 6: 565-577, 2015.

35. Pan X, Zhang X, Sun H, Zhang J, Yan M and Zhang H: Autophagy inhibition promotes 5 -fluorouraci-induced apoptosis by stimulating ROS formation in human non-small cell lung cancer A549 cells. PLoS One 8: e56679, 2013.

36. Rosenberg B: Fundamental studies with cisplatin. Cancer 55: 2303-16, 1985.

37. Hecquet B, Vennin P, Fournier C, Lefebvre JL, Caty A, Bonneterre J, Adenis L and Demaille A: Platinum concentration in human tumors of head and neck, uterine cervix, and breast following treatment with cisplatin. Cancer Chemother Pharmacol 15: 310-312, 1985.

38. Ohtsu A, Shimada Y, Shirao K, Boku N, Hyodo I, Saito H, Yamamichi N, Miyata Y, Ikeda N, Yamamoto S, et al; Japan Clinical Oncology Group Study (JCOG9205): Randomized phase III trial of fluorouracil alone versus fluorouracil plus cisplatin versus uracil and tegafur plus mitomycin in patients with unresectable, advanced gastric cancer: The Japan Clinical Oncology Group Study (JCOG9205). J Clin Oncol 21: 54-59, 2003. 